\title{
Respiratory Syncytial Virus (RSV) in Infants Hospitalized for Acute Lower Respiratory Tract Disease: Incidence and Associated Risks
}

\author{
Adriana Gut Lopes Riccetto, José Dirceu Ribeiro, \\ Marcos Tadeu Nolasco da Silva, Renata Servan de Almeida, \\ Clarice Weis Arns and Emílio Carlos Elias Baracat
}

\begin{abstract}
Respiratory syncytial virus (RSV) is one of the main causes of acute lower respiratory tract infections worldwide. We examined the incidence and associated risks for RSV infection in infants hospitalized in two university hospitals in the state of São Paulo. We made a prospective cohort study involving 152 infants hospitalized for acute lower respiratory tract infections (ALRTI) in two university hospitals in Campinas, São Paulo, Brazil, between April and September 2004. Clinical and epidemiological data were obtained at admission. RSV was detected by direct immunofluorescence of nasopharyngeal secretions. Factors associated with RSV infection were assessed by calculating the relative risk (RR). The incidence of RSV infection was $17.5 \%$. Risk factors associated with infection were: gestational age less than 35 weeks (RR: 4.17; 95\% confidence interval (CI) 2.21-7.87); birth weight less than or equal to 2,500 grams (RR: 2.69; 95\% CI 1.345.37); mother's educational level less than five years of schooling (RR: 2.28 ; 95\% CI 1.13-4.59) and pulse oximetry at admission to hospital lower than 90\% (RR: 2.19 ; 95\% CI 1.10-4.37). Low birth weight and prematurity are factors associated with respiratory disease due to RSV in infants. Low educational level of the mother and poor socioeconomic conditions also constitute risk factors. Hypoxemia in RSV infections at admission indicates potential severity and a need for early oxygen therapy.

Key Words: Acute respiratory infection, respiratory syncytial virus, risk factors.
\end{abstract}

Respiratory syncytial virus (RSV) is the main cause of acute lower respiratory tract infections (ALRTI) in the first year of life, resulting in hospitalization of nearly 120,000 children every year in the United States [1]. In developing countries, it is estimated that $0.5 \%$ to $2 \%$ of all children with RSV disease are hospitalized; of these, $7 \%$ to $21 \%$ develop respiratory insufficiency, leading to death in 0.5 to $1.5 \%$ of hospitalized cases [2-5]. The incidence of RSV infection ranges from 15.8 to $32.2 \%$ in studies conducted in Brazilian university hospitals [6,7]. Infections due to RSV generally occur as annual outbreaks. In South America, they take place during autumn and winter. In a study conducted at a university hospital in the city of São Paulo (1995 to 1999) involving 248 children with ALRTI, $90.4 \%$ of the RSV-infection cases occurred between April and July [7].

Severe RSV infections occur in young infants that are borne prematurely, have bronchopulmonary dysplasia, congenital heart disease, congenital or acquired immunodeficiency, or cystic fibrosis [8-10]. A review of 76 articles published in the MEDLINE system (2003) revealed a high percentage of severe cases of RSV infection in healthy patients [11]. In these cases, the risk factors were: male sex,

Received on 12 July 2006; revised 13 September 2006.

Address for correspondence: Dr. Adriana Gut Lopes Riccetto. Rua Washington Luís, 752, apto 112; Centro, Americana - S.P; Zip code: 13465-520. Phone: (19) 34621514; Fax: (19) 34065900. E-mail: a.riccetto@uol.com.br.

The Brazilian Journal of Infectious Diseases 2006;10(5):357-361. (C) 2006 by The Brazilian Journal of Infectious Diseases and Contexto Publishing. All rights reserved. age less than six months, being born during the first half of the annual season of RSV circulation and agglomeration (larger number of siblings and day care attendance). In this review, factors considered as non-risk associated were: ethnicity, low maternal educational level, socioeconomic classification, duration of breastfeeding and malnutrition. Nevertheless, other authors consider factors such as parental smoking, indoor pollution and family history of atopy as risk factors for severe RSV infections [12-14].

We examined the incidence and associated risks for RSV infection in hospitalized infants.

\section{Material and Methods}

We conducted a prospective cohort study in two university hospitals in Campinas, São Paulo, Brazil. Individuals responsible for the patients signed an informed consent form that permitted the patients' participation in the study; the research project was approved by the local Research Ethics Committee.

The infants in this study were hospitalized from April 1 to September 30, 2004; their ages ranged from 0 to 12 months. The initial diagnosis of ALRTI was based on clinical symptoms of tachydyspnea, abnormal lung sounds and pulse oximetry lower than $95 \%$. Children with respiratory diseases that lasted for more than seven days and those with hemodynamic instability, cardiopathies and chronic lung diseases were excluded.

Epidemiological data considered were: sex, ethnicity, age in months, birth weight, gestational age, breastfeeding duration, presence of concomitant diseases, previous 
wheezing episodes, number of smokers in the household, number of household members, mother's age and educational level. Physical examination at admission examined the heart and respiratory rates, cyanosis and pulse oximetry. An assessment was made during hospitalization, of hospitalization time, duration of oxygen therapy, need for mechanical ventilation, and use of antibiotics and corticosteroids. The assisting physician indicated mechanical pulmonary ventilation (MPV) according to clinical and blood gas criteria. RSV was detected in the nasopharyngeal secretions of the patients using the $\mathrm{CHEMICON}^{\circledR}$ KIT for Direct Immunofluorescence (DIF). Patients were divided into two groups according to DIF results and compared using either the Chi square test or Fischer's exact test. The Mann-Whitney test was applied to compare the continuous or ordinal measures of both groups. The relative risk (RR) was calculated for all variables. The significance level adopted for the statistical tests was $5 \%$ and the confidence interval (CI) for relative risk was $95 \%$.

The computer programs used were SPSS for Windows 11.0 and SAS System for Windows 8.2.

\section{Results}

One hundred and fifty-two patients were included in the study, but RSV DIF results were only available for 149. Twentysix $(17.5 \%)$ of these were RSV positive. The mean age of the patients was 4.45 months, being 93 males (61.2\%) and 59 females (38.8\%) (Figure 1); 92\% of the RSV-infection cases occurred between April and June (Figure 2). When epidemiological data were compared with RSV presence in the DIF test, a significant association with RSV was found for the following variables: gestational age, with a higher risk for infants born with less than 35 weeks $(\mathrm{P}<0.001 ; \mathrm{RR}=4.17,95 \%$

Figure 1. Distribution (frequency in percent) by age of infants under 12 months old (x axis) admitted for acute lower respiratory tract infection at two university hospitals in Campinas, São Paulo, Brazil, between April and September 2004.

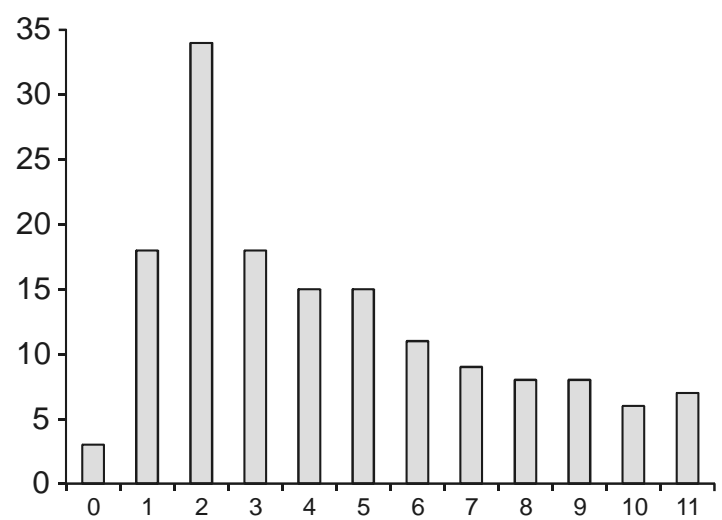

CI: 2.21-7.87); birth weight lower than 2,500g ( $\mathrm{P}=0.0052$; $\mathrm{RR}=2.69,95 \% \mathrm{CI}: 1.34-5.37)$; and mother's schooling less than five years $(\mathrm{P}=0.0223, \mathrm{RR}=2.28,95 \% \mathrm{CI}$ : 1.13-4.59) (Table 1). There were no differences between the DIF+ and DIF- groups in relation to the other variables analyzed, including age, sex, breastfeeding, previous illnesses, previous wheezing episodes, maternal age, smokers in the family and number of household members (Table 1).

When we examined clinical variables, the only patient who presented cyanosis was positive for RSV in the DIF test. The use of corticosteroids ( $\mathrm{P}=0.0584 ; \mathrm{RR}=2.24,95 \% \mathrm{CI}$ : $1.07-4.67)$ and pulse oxymetry lower than $90 \%(\mathrm{P}=0.027$; $\mathrm{RR}=2,19,95 \%$ CI: 1.10-4.37) were related to the presence of RSV (Table 2). The other variables, such as tachypnea at admission, prolonged hospitalization, use of oxygen therapy for more than 10 days, use of antimicrobials and rehospitalization were not significantly different between DIF+ and DIF- groups. When we examined tachycardia, the infants with negative DIF results had a higher heart rate than the DIF-positive group $(\mathrm{P}=0.0335 ; \mathrm{RR}=0.39,95 \% \mathrm{CI}: 0.16-0.99)$ (Table 2).

Among the patients who underwent MPV, 6/21 had a positive DIF for RSV. A comparison between DIF+ and DIFgroups showed no increased risk for MPV due to RSV infection (Fischer test, $\mathrm{P}=0.2097)(\mathrm{RR}=1.83$; 95\% CI: 0.83-4.02). No differences were found in MPV time in DIF-positive (mean=6.5 days; median $=6$ days) compared to DIF-negative patients ( mean=7.07 days; median=6 days).

\section{Discussion}

In our cohort of patients, RSV infected $17.5 \%$ of the infants from April to June, corroborating the findings of other studies involving patients hospitalized in the same region of the country (15.8\% to $32.2 \%$ of cases) [7]. Since the results are

Figure 2. Distribution (frequency in percent) by month of the year and presence of respiratory syncytial virus (RSV) in infants less than 12-months old admitted for acute lower respiratory tract infection at two university hospitals in Campinas, São Paulo, Brazil, between April and September 2004.

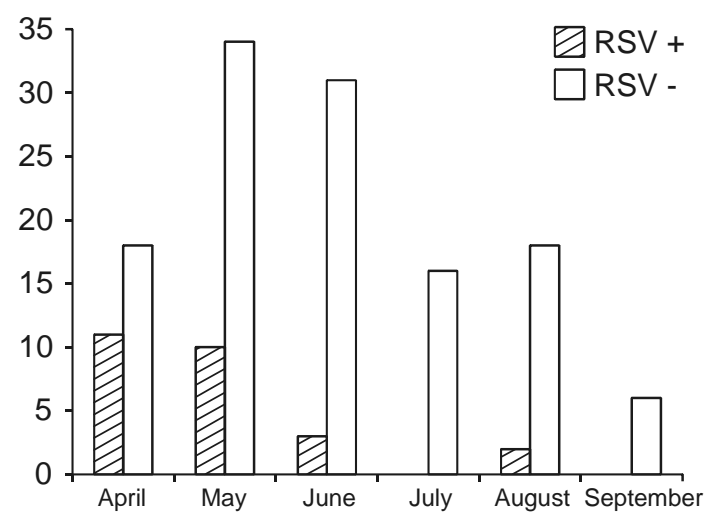


Table 1. Relationship between epidemiological variables and respiratory syncytial virus (RSV) investigation using direct immunofluorescence (DIF) on nasopharyngeal secretions from 152 infants with acute lower respiratory tract disease

\begin{tabular}{lcccc}
\hline Variable & $\begin{array}{c}\text { DIF positive } \\
\text { group (presence/ } \\
\text { absence) }\end{array}$ & $\begin{array}{c}\text { DIF negative } \\
\text { group (presence/ } \\
\text { absence) }\end{array}$ & $\begin{array}{c}\text { Relative Risk } \\
\text { (95\% CI ) }\end{array}$ & $\begin{array}{c}\text { Value of P } \\
\text { Age }<3 \text { months/>3months }\end{array}$ \\
Sex male/female & $9 / 17$ & $46 / 77$ & $0.90(0.43-1.89)$ & 0.6789 \\
Ethnicity Caucasian & $16 / 10$ & $76 / 47$ & $0.99(0.48-2.03)$ & 0.9810 \\
Gestational Age $<35$ weeks at birth & $14 / 12$ & $83 / 40$ & $0.62(0.31-1.25)$ & 0.1851 \\
Birth weight <2,500 g & $7 / 19$ & $5 / 117$ & $4.17(2.21-7.87)$ & $<0.001$ \\
Maternal breastfeeding <1 month & $8 / 18$ & $13 / 109$ & $2.69(1.34-5.37)$ & 0.0052 \\
Previous diseases & $13 / 13$ & $46 / 77$ & $1.52(0.76-3.05)$ & 0.2326 \\
Previous wheezing & $7 / 19$ & $31 / 92$ & $1.08(0.49-2.36)$ & 0.8550 \\
Mother's age $<20$ years & $8 / 18$ & $33 / 90$ & $1.17(0.55-2.48)$ & 0.0936 \\
Mother's schooling < 5 years & $10 / 16$ & $30 / 92$ & $1.68(0.84-3.40)$ & 0.1482 \\
Smoking in the family & $10 / 15$ & $23 / 98$ & $2.28(1.13-4.59)$ & 0.0223 \\
More than five household members & $11 / 15$ & $45 / 77$ & $1.20(0.59-2.43)$ & 0.6047 \\
\hline
\end{tabular}

Table 2. Relationship between clinical variables and respiratory syncytial virus (RSV) investigation using direct immunofluorescence (DIF) in nasopharyngeal secretions from 152 infants with acute lower respiratory tract disease

\begin{tabular}{lcccc}
\hline Variable & $\begin{array}{c}\text { DIF positive } \\
\text { group (presence/ } \\
\text { absence) }\end{array}$ & $\begin{array}{c}\text { DIF negative } \\
\text { group (presence/ } \\
\text { absence) }\end{array}$ & $\begin{array}{c}\text { Relative Risk } \\
(\mathbf{9 5 \%} \text { CI })\end{array}$ & $\begin{array}{c}\text { Value of P } \\
\text { Tachypnea }\end{array}$ \\
Tachycardia & $12 / 13$ & $69 / 54$ & $0.76(0.37-1.56)$ & 0.4584 \\
O2 Saturation $<90 \%$ & $10 / 16$ & $51 / 72$ & $0.39(0.16-0.99)$ & 0.0335 \\
Hospitalization $>$ 10 days & $7 / 19$ & $23 / 100$ & $2.19(1.10-4.37)$ & 0.027 \\
Oxygen therapy > 10 days & $6 / 20$ & $29 / 94$ & $1.16(0.53-2.52)$ & 0.7173 \\
Use of antimicrobials & $8 / 18$ & $23 / 100$ & $1.24(0.55-2.81)$ & 0.6085 \\
Corticoid therapy & $7 / 19$ & $45 / 78$ & $0.80(0.37-1.72)$ & 0.5373 \\
Rehospitalization & $1 / 25$ & $14 / 109$ & $2.24(1.07-4.67)$ & 0.0584 \\
\hline
\end{tabular}

similar to those from North America, infections due to RSV may be a consequence of lower temperatures; but this relationship has still not been completely clarified. Due to the increased number of cases during this season, it is speculated that the main responsible factors are the mothers' asymptomatic infections, larger agglomerations of children, infection of patients with chronic lung diseases and immunocompromised patients in the community $[11,16]$.

In our study, the unfavorable clinical outcome of the patients was limited to the need for MPV, since no deaths occurred. Twenty-one patients needed MPV (13.8\%) and of these, six were from the RSV-positive group. In the northern hemisphere, the need for MPV among children infected by RSV ranged from 6.4 to $15.8 \%$ of hospitalized patients [2,1719]; another report cites $39 \%$ among patients in the southern hemisphere (Uruguay) [20]. However, RSV in this cohort did not indicate an increased risk for MPV. Probably other unidentified viral agents, such as metapneumovirus, which is related to the clinical presentation of acute viral bronchiolitis or the influenza virus, were present in patients that evolved to MPV, as reported by recent studies [21-24]. A study conducted on 1,505 children with acute viral bronchiolitis demonstrated metapneumovirus in $2.8 \%$, RSV in $9.5 \%$, influenza virus in $15.3 \%$ of the patients and a co-infection rate of $16.7 \%$ [24]. Another study revealed that metapneumovirus associated with RSV infection increased the risk of being admitted to the intensive care unit tenfold [21].

The risk for acquiring RSV infection was greatly increased for those patients whose gestational age was less than 35 weeks or whose birth weight was less than 2,500 grams, as previously described by other authors $[8,14]$. Leader et al. conducted a study that consisted of more than 718,000 assessments performed on children with acute respiratory disease caused by RSV from 1997 to 2000. They found a significant risk for mortality among infants born with gestational age less than 35 weeks or birth weight less than 2,500 grams [25]. The high susceptibility of premature infants to diseases caused by RSV is believed to be due to the fact 
that during the third gestational trimester, maternal immunoglobulin $\mathrm{G}(\mathrm{IgG})$, which provides partial protection against this infection, is transported through the placenta and during this period, the diameters of the bronchioles and alveoli also increase greatly [8,9].

The risk for acquiring RSV infections was 2.28 times greater among infants with less-educated mothers. Some researchers have also reported a correlation between higher mortality and maternal age below 20 years [25] or low education level. However, an assessment of articles published on MEDLINE over a period of 30 years revealed that most of the studies did not establish this correlation, even when the factors age and schooling were analyzed apart from the other socioeconomic factors, such as low income and agglomeration [11].

Physical assessment of the patients at admission revealed that pulse oximetry values lower than $90 \%$ was a risk factor for RSV infection. While some researchers consider that clinical signs of respiratory discomfort, cyanosis and a compromised general condition are sufficient for establishing tissue hypoxia [26], others believe that this assessment is limited, especially in previously-healthy children with low risk for mechanical ventilation [27]. In general, risk factors at one location may not be considered important in another due to different criteria applied at hospital admission and discharge $[18,20]$.

In our cohort, RSV infection did not constitute a risk factor for MPV. MPV was associated with a longer period of hospitalization and use of antibiotics. In these patients, the severity of clinical presentation was probably determined by individual immune responses and not by the presence of RSV $[29,30]$.

Identification of the viral agents involved in ALRTI by nasopharyngeal aspirates helps in instituting measures to avoid nosocomial viral infection in hospitalized infants. Studies conducted in university hospitals in the state of São Paulo demonstrated RSV nosocomial infection rates between 7.6 and $14.1 \%$ [31,32]. Measures to control viral infections acquired in hospitals as well as identification of the virus in aspirated nasopharyngeal secretion are already routine procedures in other countries; this helps considerably in reducing hospital costs [33].

The results of our follow-up study show that the identification of RSV and continued monitoring in hospitalized infants with ALRTI can reduce the impact of this infection in infants. Parents should be instructed on hand washing before contacting their newborn, especially for premature infants and those with low birth weights.

\section{References}

1. Shay D.K., Holman R.C., Newman D., et al. Bronchiolitisassociated hospitalizations among US children, 1980-19996. JAMA 1999;282:1440-6.

2. Brandenburg A.H., Jeannet P.Y., Steensel-Moll H.A., et al. Local Variability in respiratory syncytial virus disease severity. Arch Dis Child 1997;77:410-14.
3. Fletcher J.N., Smyth R.L., Thomas H.M., et al. Respiratory syncytial virus genotypes and disease severity among children in hospital. Arch Dis Child 1997;77:508-11.

4. Loscertales M.P., Roca A., Ventura P.J., et al. Epidemiology and clinical presentation of respiratory syncytial virus infection in a rural area of southern Mozambique. Pediatr Infect Dis J 2002;21:148-55.

5. Mcnamara P.S., Smyth R.L. The pathogenesis of respiratory syncytial virus disease in childhood. Br Med Bull 2002;61:1328.

6. Cintra O.A.L., Owa M.A., Machado A.A., et al. Occurence and severity of infections caused by subgroup A and B respiratory syncytial virus in children in southeast Brazil. J Med Virol 2001;65:408-12.

7. Vieira S.E., Gilio A.E., Miyao C.R., et al. Sazonalidade do vírus respiratório sincicial na cidade de São Paulo, SP. Pediatria (São Paulo) 2002;24(1/2):73-4.

8. Welliver R.C. Review of epidemiology and clinical risk factors for severe respiratory syncytial virus (RSV) infection. J Pediatr 2003; 143:S112-S7.

9. Weisman L. Populations at risk for developing respiratory syncytial virus and risk factors for respiratory syncytial virus severity: infants with predisposing conditions. Pediatr Infect Dis J 2003;22:S33-S9.

10. Meisner H.C. Selected populations at increased risk from respiratory syncytial virus infection. Pediatr Infect Dis J 2003;22(2):S40-5.

11. Simoes E.A.F. Environmental and demographic risk factors for respiratory syncytial virus lower respiratory tract disease. J Pediatr 2003; 143:S118-S26.

12. Sant'Anna C.C., D'Elia C. Bronquiolitis. In: Benguigui Y, Antuñano FJL, Schmunis G, Yunes J, eds. Infecciones respiratorias en niños. Organización Panamericana de la salud, Washington, 1997, p. 261-80.

13. Denny J.R.F.W. The impact of respiratory virus infections on the world's children. In: Asthma and respiratory infections. Skoner DP (ed). Marcel Deker, NY, 2001. p. 1-22.

14. Lannari M., Giovannini M., Giuffré L., et al. Prevalence of respiratory syncytial virus infection in italian infants hospitalized for acute lower respiratory tract infections, and association between respiratory syncytial virus infection risk factors and disease severity. Pediatr Pulmonol 2002;33:458-65.

15. Jorden R.C. "Multiple Trauma" in Emergency Medicine Concepts and Clinical Practice 3rd ed.; Rosen P, Barkin R. (eds).Mosby-Year Book, Inc, 1982. p. 281-2.

16. Stenballe L.G., Devasundaram J.K., Simoes E.A.F. Respiratory syncytial virus epidemics: the ups and downs of a seasonal virus. Pediatr Infect Dis J 2003;22:S21-S32.

17. Purcell K., Fergie J. Driscoll Children's Hospital Respiratory Syncytial Database. Risk factors treatment and hospital course in 3308 infnts and young children, 1991 to 2002. Pediatr Infect dis J 2004;23:418-23.

18. Kneyber M.C.J., Moons K.G.M., De Groot R., Moll H.Á. Prediction of duration of hospitalization in respiratory syncytial virus infection. Pediatric Pulmonology 2002;33:453-7.

19. Willson D.F., Landrigan C.P., Horn S.D., Smout R.J. Complications in infants hospitalized for bronchiolitis or respiratory syncytial virus pneumonia. J Pediatr 2003; $143:$ S142-S9. 
20. Bello Pedrosa O., Langenhin M., Pujadas Ferrer M.A., et al. Severe infections due to respiratory syncytial virus in infants under three months of age. Incidence in patients without common risk factors. Arch Pediatr Urug 2001;72(supl):20-5.

21. Semple M.G., Cowell A., Dove W., et al. Dual infections of infants by human metapneumovirus and human respiratory syncytial virus is strongly associated with severe bronchiolitis. J Infect Dis 2005; 191(3):382-6.

22. Garofalo R.P., Hintz K.H., Hill V., et al. A comparison of epidemiologic and immunologic features of bronchiolitis caused by influenza virus and respiratory syncytial virus. J Med Virol 2005;75(2);282-9.

23. Arostegi Kareaga N., Montes M., Perez-Yarza E.G., et al.Clinical Characteristics of children hospitalized for influenza virus infection. An Pediatr (Barc.) 2005;62(1):5-12.

24. Bosis S., Esposito S., Niesters H.G., et al. Impact of human metapneumovirus in childhood: comparison with respiratory syncytial virus and influenza viruses. J med Virol 2005;75(1):101-4.

25. Leader S., Kohlhase K. Recent trends in severe respiratory syncytial virus (RSV) among US infants, 1997-2000. J Pediatr 2003; 143:S127-S32.

26. Weber M.W., Usen S., Jaffar S., Mulholland E.K. Predictors of hypoxaemia in hospital admissions with acute lower respiratory tract infection in developing country. Arch Dis Child 1997;76:310-4.
27. Brooks A.M., McBride J.T., McConnochie K.M., et al. Predicting deterioration in previously healthy infants hospitalized with respiratory syncytial virus infection. Pediatrics 1999;104(3):463-7.

28. Opavsky M.A., Stephens D., Wang E.E.L. Testing models predicting severity of respiratory syncytial virus infection on the PICNIC RSV database. Arch Pediatr Adolesc Med 1995; 149 : 1217-20.

29. Richardson J.Y., Ottolini M.G., Pletneva L., et al. Respiratory Syncytial Virus (RSV) infection induces cyclooxygenase 2: a potential target for RSV therapy. J Immunol 2005; 174(7):4356-64.

30. Stark J.M., Khan A.M., Chiappetta C.L., et al. GN.Immune and functional role of nitric oxide in a mouse model of respiratory syncytial virus infection. J Infect Dis 2005; 191(3):387-95.

31. Vieira S.E., Gilio A.E., Miyao C.R., et al. Infecção nosocomial pelo vírus respiratório sincicial em enfermaria de pediatria. Pediatria (São Paulo) 2002;24(1/2):17-24.

32. Diniz E.M., Vieira R.A., Ceccon M.E., et al. Incidence of respiratory viruses in preterm infants submitted to mechanical ventilation. Rev Inst med Trop Sao Paulo 2005;47(1):37-44.

33. MaCartney K.K., Gorelick M.H., Manning M.L., et al. Nosocomial respiratory syncytial virus infections: the cost effectiveness and cost-benefit of infection control. Pediatrics 2000;106:520-6. 